\title{
Justification of the Coexistence of Formal and Informal Reciprocal Loans in Developing Countries
}

\author{
Jianmei Zhao1, Ruihan Liu' ${ }^{2 *}$ \\ ${ }^{1}$ China Academy of Public Finance and Public Policy, Central University of Finance and Economics, Beijing, China \\ ${ }^{2}$ College of Economics and Management, Beijing University of Agriculture, Beijing, China \\ Email: *liuruihan@bua.edu.cn
}

How to cite this paper: Zhao, J.M. and Liu, R.H. (2017) Justification of the Coexistence of Formal and Informal Reciprocal Loans in Developing Countries. Theoretical Economics Letters, 7, 1865-1872. https://doi.org/10.4236/tel.2017.76127

Received: October 5, 2017

Accepted: October 28, 2017

Published: October 31, 2017

Copyright (c) 2017 by authors and Scientific Research Publishing Inc. This work is licensed under the Creative Commons Attribution International License (CC BY 4.0).

http://creativecommons.org/licenses/by/4.0/

\section{(c) (i) Open Access}

\begin{abstract}
This paper provides a new justification for the coexistence of formal and informal reciprocal loans in developing countries. We develop an investment model capable of comparing the financing costs of different financing alternatives. Notably, the reciprocal feature of interest-free loans from friends imposes an agnostic obligation on the borrower and generates implicit financing costs. The diverse financing outcomes hinge on the comparison of the explicit costs of formal loans and the implicit costs of reciprocal loans from friends.
\end{abstract}

\section{Keywords}

Coexistence, Reciprocal Loan, Financing Costs, China

\section{Introduction}

The empirical literature has extensively documented the coexistence of formal and informal finance in developing countries [1]. Formal finance refers to collateralized loans from banks, credit cooperatives and government agencies, whereas typically informal finance includes loans from moneylenders without collateral requirements but relatively high interest charges and small collateral-free and interest-free loans from friends or relatives.

Theoretical explanations of the coexistence of formal and informal finance have taken two distinctive approaches. One assumes that poorer borrowers only have recourse to informal lenders with access to institutional credit who then relend to them [2] [3]. The other emphasizes the screening difficulty and limited contract enforcement encountered by formal financial agencies; by imposing limits on the amount of credit, the grants from formal institutions may 
trigger constrained borrowers to turn to informal sectors for additional credit [4] [5].

The above explanations can explain the coexistence of formal and informal loans from money lenders to a certain extent, but they face challenges in explaining the coexistence of formal loans and reciprocal loans from friends. First, both arguments potentially assume that formal finance is the first financing choice. However, there is no reason to deny that informal finance could be preferred. Second, the first argument justifies the coexistence of formal and informal loans by arguing that the use of informal finance from money lenders is borrowers' last resort, given that they are unable to access cheaper formal finance. Yet, reciprocal loans from friends entail neither the provision of collateral nor interest payments. Thus, the above argument is not convincing in explaining the coexistence of formal loans and reciprocal loans from friends. Third, viewing informal loans as spillovers from formal loans goes against the empirical evidence from the credit market in that despite the increased injection of formal credit, the demand for formal loans is still low in India [6] and reciprocal loans from friends continue to dominate the credit market in developing countries, such as China [7]. Reciprocal loans from friends are by no means an overflow from formal finance.

This note supplements the literature by providing a new justification for the coexistence of formal and reciprocal loans from friends in developing countries. We develop a general model of investment and apply it to the cases of formal and reciprocal loans to determine when it is economical to use, either separately or together. Notably, the reciprocal feature of interest-free loans from friends imposes an agnostic obligation on the borrower and generates implicit financing costs. The final financing outcome hinges on the agent's complete evaluation and comparison of the aggregated financing costs from all available financing alternatives.

The remainder of this paper is organised as follows. In Section 2, we develop an investment model composed of two types of investment, and the condition for the agent to undertake such investment. In Section 3, we specify two sources of financing and potential financing costs that correspond with each type of financing source. We analyze possible financing outcomes by comparing financing costs from different financing channels in Section 4. Section 5 concludes it.

\section{Investment Model}

The primary assumptions of our investment model include: 1) Agents (or borrowers) are profit maximizers and they differ in terms of the endowed assets $(A)$ that can be committed as collateral to secure loans. 2) Agents allocate internal capital $(K)$ between two activities: a self-financing conservative investment and a higher return but riskier investment with the aid of external credit. 3) The condition for agents to undertake an investment is the expected income of the investment is greater or equal to their reservation revenue. 
Agents face two types of investment, a conservation investment and a risky investment. The conservative investment offers the agent a stable return with an income level of $q=Q(K ; Z)$, where $Z$ reflects the agent's personal relationships with others. The riskier investment generates high income, $Q^{H}$, with probability $\pi$, or low income, $Q^{L},\left(Q^{L}<q<Q^{H}\right)$ with probability $1-\pi$. The uncertainties of the riskier investment entail a risk premium $\left(R P_{1}\right)$. The external credit needed, $B^{*}=f(A, C ; \theta, Z)$, is a function of the securable assets $(A)$, the financing cost $(C)$, the agent's subjective risk factor $(\theta)$, determining the risk premium, and $Z$ as defined above. The financing $\operatorname{cost}(C)$ involves a fixed application fee $\left(C_{f}\right)$, a variable financing cost $\left(C_{v}\right)$ associated with the loan size and interest and a default cost $\left(C_{d}\right)$ if the borrower defaults on the loan. Only when the expected income from the riskier investment is greater than that from the self-financing investment does the agent undertake the riskier investment:

$$
\pi\left(Q^{H}-C_{v}-C_{f}\right)+(1-\pi)\left(Q^{L}-C_{v}-C_{f}-C_{d}\right)-R P_{1}>q
$$

Re-arranging Equation (1), we get $\pi Q^{H}+(1-\pi)\left(Q^{L}-C_{d}\right)>q+R P_{1}+C_{v}+C_{f}$. It is possible that the agent's loan application will be rejected by financial providers with a probability $(\delta)$, which entails another type of risk premium $\left(R P_{2}\right)$ for risk-averse agents. A successful loan application enables the agent to undertake the riskier investment; on the other hand, loan rejection will induce the agent to revert to the conservative investment. Concomitant with the sunk fixed application fees $\left(C_{f}\right)$, the expected income levels for the approved loan $\left(E\left(Y_{\text {apv }}\right)\right)$ and the rejected loan $\left(E\left(Y_{\text {rit }}\right)\right)$ are:

$$
\begin{gathered}
E\left(Y_{\text {apv }}\right)=\pi Q^{H}+(1-\pi)\left(Q^{L}-C_{d}\right)-C_{v}-C_{f}-R P_{1} \\
E\left(Y_{\mathrm{rjt}}\right)=q-C_{f}
\end{gathered}
$$

Concerning uncertainties in the loan application, the agent chooses the riskier investment conditional on:

$$
(1-\delta) E\left(Y_{\text {apv }}\right)+\delta E\left(Y_{\text {rit }}\right)-R P_{2}>q
$$

Defining the agent's expected return as $\mathrm{E}(Y)=\pi Q^{H}+(1-\pi) Q^{L}$ and rearranging the terms in Equation (4), we obtain:

$$
\mathrm{E}(Y)>\gamma=q+R P_{1}+C_{v}+\frac{R P_{2}+C_{f}}{1-\delta}+(1-\pi) C_{d}
$$

The summation of the right-hand terms is the reservation revenue $(\gamma)$ composed of conservative return $(q)$, risk premium associated with investment uncertainly $\left(R P_{1}\right)$, and financing costs $\left(C_{v}+\frac{R P_{2}+C_{f}}{1-\delta}+(1-\pi) C_{d}\right)$ for the agent to undertake the riskier investment. As the expected return will be the same whether the external financing is from formal or informal reciprocal loans, financing outcomes with lower costs imply lower reservation revenue and greater potential profit for the agent. 


\section{Financing Channels}

Given the investment decision, we further assume that agents face two types of external financing sources. One is formal loans from financial institutions, such as loans from commercial banks or government financial institutions, the other is informal reciprocal loans amongst friends without interest charges. Agents prefer cheaper financing sources when they require external financing.

Our discussion of financing channels focuses on formal loans and interest-free loans from friends or a combination of the two ${ }^{1}$. Formal lenders selectively issue loans, $B^{F}\left(B^{*}, A^{F} ; \mu^{F}, \varphi\right)$, to a subset of applicants based on their loan size $\left(B^{*}\right)$, securable assets $\left(A^{F}\right)$, the formal lender's financial capacity $\left(\mu^{F}\right)$ and formal lenders' subjective risk attitude towards the borrower $(\varphi)$. Assuming that the rejection probability for the formal loan is $\delta^{F}\left(B^{*}, A^{F} ; \mu^{F}, \varphi\right), \delta^{F}$ is related positively to loan size $\left(B^{*}\right)$ and the lender's risk attitude $(\varphi)$, but is related negatively to the borrower's securable assets $\left(A^{F}\right)$ and the lender's financial capacity $\left(\mu^{F}\right)$. When the borrower proposes a larger loan size and the lender considers the borrower to be riskier, the borrower is more likely to be rejected $\left(\frac{\partial \delta^{F}}{\partial B^{*}}>0, \frac{\partial \delta^{F}}{\partial \varphi}>0\right)$. On the other hand, the more securable assets offered and the stronger financial capacity of the formal lender $\left(\mu^{F}\right)$, the more likely it is that the loan will be approved $\left(\frac{\partial \delta^{F}}{\partial A^{F}}<0, \frac{\partial \delta^{F}}{\partial \mu^{F}}<0\right)$.

The use of the formal loan incurs a fixed application fee $\left(C_{f}^{F}\right)$ and variable financing costs $\left(C_{v}^{F}=r^{F} B^{F}\right)$ associated with the risk-adjusted interest rate $\left(r^{F}\right)$ and the loan size $\left(B^{F}\right)$. If the investment fails, the agent faces the financing costs $\left(C_{d}^{F}=C_{f}^{F}+A^{F}\right)$, composed of unrecovered application fee $\left(C_{f}^{F}\right)$ and collateral assets $\left(A^{F}\right)$ acquired by the lender.

In contrast, informal reciprocal loans from friends entail neither interest $\left(r^{I}=0\right)$ nor collateral $\left(A^{I}=0\right)$ and the costs of asking for a reciprocal loan can be negligible $\left(C_{f}^{I}=0\right)$. Such loans usually occur among mutually acquainted parties in the neighbourhood. Lending decisions by friends, $B^{I}\left(B^{*}, Z ; \mu^{I}, O\right)$, depend upon the proposed loan size $\left(B^{*}\right)$, the borrower-lender relationship $(Z)$, the informal lender's financial status $\left(\mu^{I}\right)$ and the opportunity cost of capital for the lender $(O)$. Essentially, the absence of interest charges does not imply zero financing costs. Rather, the reciprocal loan initiated by the borrower simultaneously creates an informal, trust-based obligation to the lender. The borrower maybe unsure about the exact form of further benefits offered to the lender, but such additional benefits is critical and it generates a certain "debt of gratitude", $V\left(B^{I}, O ; \theta, Z\right)$, by nature the implicit costs in reciprocal loans. As a result, this implicit costs may discourage the borrower from using the interest free loans from friends. As a larger loan size and better opportunity costs of ${ }^{1}$ Loans from money lenders are not considered for two reasons: i) such loans are considered unfair by policymakers, who argue that money lenders take advantage of their position to exploit poor borrowers and thus they are prohibited in some countries, such as China; ii) it is widely recognized that loans from money lenders are more expensive than formal loans. 
capital cause grater economic loss to the lender, the "debt of gratitude" should be related positively to the reciprocal loan size $\left(\frac{\partial V\left(B^{I}, O ; \theta, Z\right)}{\partial B^{I}}>0\right)$ and the opportunity cost of lender's capital $\left(\frac{\partial V\left(B^{I}, O ; \theta, Z\right)}{\partial O}>0\right)$. The "debt of gratitude" is also associated positively with the subjective attitude of the borrower $(\theta)$. The heavier the borrower assesses the future obligation to be, the greater the value of such obligation $\left(\frac{\partial V\left(B^{I}, O ; \theta, Z\right)}{\partial \theta}>0\right)$. But the "debt of gratitude" is related negatively to the borrower-lender relationship, as a closer borrower-lender relationship provides more flexible ways for the borrower to reciprocate in the future $\left(\frac{\partial V\left(B^{I}, O ; \theta, Z\right)}{\partial Z}<0\right)$.

The implicit obligation involved in reciprocal loans is also critical to the lender, who may be entirely unclear concerning the exact form of this future obligation, other than the repayment of the principal $\left(B^{I}\right)$. Nonetheless, such future obligation must be balanced with the opportunity cost of capital $(O)$ in the lender's cost-benefit analysis so that the lender can make decisions on the loan. We assume the rejection probability of reciprocal loan to be $\delta^{I}\left(B^{*}, Z ; \mu^{I}, O\right)$. $\delta^{I}$ is related positively to loan size $\left(B^{*}\right)$ and the costs of capital $(O)$. A larger loan size and greater opportunity costs of capital to the lender are more likely to result in the loan being rejected $\left(\frac{\partial \delta^{I}}{\partial B^{*}}>0, \frac{\partial \delta^{I}}{\partial O}>0\right)$. Meanwhile, $\delta^{I}$ is related negatively to the borrower-lender relationship $(Z)$ and the informal lender's financial capacity $\left(\mu^{I}\right)$. The greater financial capacity of the lender and a closer relationship with the borrower are more likely to see the reciprocal loan approved $\left(\frac{\partial \delta^{I}}{\partial Z}<0, \frac{\partial \delta^{I}}{\partial \mu^{I}}<0\right)$.

The lack of collateral in reciprocal loans does not discourage the agent from fulfilling his obligation, as the social enforcement imposed by close-knit communities will sanction defaulters by putting them in an isolated position, both economically and emotionally. To avoid such punishment, the borrower is incentivized to repay the principal $\left(C_{d}^{I}=B^{I}\right)$ and compensate the creditor through "generalized reciprocity", such as providing free labour, land, or draft animal services, a direct transfer in cash or in kind, or a future loan.

Summarizing, the reservation revenues for the riskier investment through formal $\left(\gamma^{F}\right)$ and reciprocal credit $\left(\gamma^{I}\right)$ sources are:

$$
\begin{gathered}
\gamma^{F}=q+R P_{1}+r^{F} B^{F}+\frac{R P_{2}^{F}+C_{f}^{F}}{1-\delta^{F}}+(1-\pi) A^{F} \\
\gamma^{I}=q+R P_{1}+V\left(B^{I}, O ; \theta, Z\right)+\frac{R P_{2}^{I}}{1-\delta^{I}}+(1-\pi) B^{I}
\end{gathered}
$$

Under the condition that the agent's external financing is not fully covered by cheaper credit sources, the agent will balance the expected income with the res- 
ervation revenue by using mixed finance $\left(\gamma^{M}\right)$ from both sources:

$$
\begin{aligned}
\gamma^{M}= & q+R P_{1}+r^{M F} B^{M F}+V\left(B^{M I}, O ; \theta, Z\right)+\frac{R P_{2}^{M F}+C_{f}^{F}}{1-\delta^{M F}} \\
& +\frac{R P_{2}^{M I}}{1-\delta^{M I}}+(1-\pi)\left[A^{M F}+B^{M I}\right]
\end{aligned}
$$

where $\delta^{M F}$ and $\delta^{M I}$ are the possibilities that the borrower will be rejected by the formal and reciprocal lenders respectively, and $R P_{2}^{M F}$ and $R P_{2}^{M I}$ are corresponding risk premiums. If the agent obtains sufficient financing, $B^{M F}+B^{M I}$ $\left(\geq B^{*}\right)$, and the expected income of the investment is greater than or equal to the reservation revenue $\left(\mathrm{E}(Y) \geq \gamma^{M}\right)$, the agent borrows simultaneously from both formal $\left(B^{M F}\right)$ and reciprocal sources of finance $\left(B^{M I}\right)$. Otherwise, insufficient financing $\left(B^{M F}+B^{M I}<B^{*}\right)$ will induce the agent to revert to the conservative investment.

Regarding different financing channels and their corresponding costs, we propose the following hypotheses $(\mathrm{H})$ :

H1: Only when the expected income of investment is greater than (at least equal to) the reservation revenue composed of financing costs, agents borrow externally;

H2: Given the same amount of expected income, agents choose financing channels with lowest reservation revenue;

H3: Agents apply mixed financing sources to fulfil their capital requirement given the expected income is larger than reservation revenue.

\section{Financing Outcomes}

The agent's financing outcomes are closely linked to the loan size, which determines the financing alternatives available. Moreover, the loan size is also a key element affecting the lender's decision. In line with empirical practice in the credit market, we categorize the loans into small versus large loans. Small loans $\left(B_{S}^{*}\right)$ are defined as those that can be provided by either formal or reciprocal lenders individually $\left(B_{S}^{*}<\mu^{F} \& B_{S}^{*}<\mu^{I}\right.$ ), whereas large loans $\left(B_{L}^{*}\right)$ can only be financed by an individual formal lender, but not a reciprocal lender due to limited financial capacity $\left(B_{L}^{*}<\mu^{F} \& B_{L}^{*}>\mu^{I}\right)$.

Most small loans are financed through reciprocal lending from friends. The reasons for this include the low opportunity cost of capital $(O)$ in developing countries, which brings less economic loss to the lender and generates a lower "debt of gratitude" for the borrower. Furthermore, the long-term established friendship between the borrower and lender $(Z)$ makes it hard for the informal lender to deny the loan. In contrast, in the case of formal lenders, small loans are exempt neither from the complicated transaction process on the part of the borrower, nor the review process of the formal lender. The greater asymmetry of information between the borrower and formal financial agencies leads formal lenders to be more conservative $(\varphi)$ concerning such loans. Therefore, the probability of formal loan rejection tends to be higher (or equivalent to) than 
that for reciprocal loans $\left(\delta^{I}\left(B_{S}^{*}, Z ; \mu^{I}, O\right) \leq \delta^{F}\left(B_{S}^{*}, A^{F} ; \mu^{F}, \varphi\right)\right)$. Accordingly, the risk premium of reciprocal loans should be less (or equal to) than that of formal loans $\left(R P_{2}^{I} \leq R P_{2}^{F}\right)$, plus the fixed application fee for formal loans $\left(C_{f}^{F}\right)$; it is likely that $\frac{R P_{2}^{F}+C_{f}^{F}}{1-\delta^{F}} \geq \frac{R P_{2}^{I}}{1-\delta^{I}}$. Furthermore, formal loans tend to be secured with collateral assets, with a value greater than or equal to the loan size $\left(A^{F} \geq B_{S}^{*}\right)$, so that $\frac{R P_{2}^{F}+C_{f}^{F}}{1-\delta^{F}}+(1-\pi) A^{F} \geq \frac{R P_{2}^{I}}{1-\delta^{I}}+(1-\pi) B_{S}^{*}$.

The comparison of formal variable financing costs $\left(r^{F} B_{S}^{F}\right)$ and the informal "debt of gratitude", $V\left(B_{S}^{I}, O ; \theta, Z\right)$, is rather subjective and contingent on the borrower's evaluation on the future obligation. In most cases, the value of the "debt of gratitude" is considered to be less than the monetary interest payments for small loans financed through reciprocal lending $\left(V\left(B_{S}^{I}, O ; \theta, Z\right)<r^{F} B_{S}^{F}\right)$. However, if the implicit obligation imposes a greater economic burden on the borrower relative to the interest payments and even offsets other cost advantages of reciprocal loans ${ }^{2}$, the borrower will resort to formal lenders rather than the reciprocal loan.

For large loans, as the large credit demand cannot be fulfilled by an individual informal lender $\left(B_{L}^{*}>\mu^{I}\right)$, the probability of loan rejection is high $\left(\delta^{I} \rightarrow 1\right)$, which inflates the financing costs for informal reciprocal lenders $\left(\frac{R P_{2}^{I}}{1-\delta^{I}} \rightarrow \infty\right)$. Therefore, borrowers in the credit market tend to opt for a formal lender, resort to multiple reciprocal lenders, or use mixed finance for their large credit needs. Assuming that all lenders make their lending decisions independently, the explicit and implicit financing costs of each financing channel could be assessed in the same way as for small loans. Summing up the financing costs for each financing channel, the borrower can compare the aggregated financing costs of each possible financing alternative and choose the favourable option.

\section{Conclusions}

This note provides a justification for the coexistence of formal and reciprocal loans in developing countries. We develop an investment model capable of comparing the financing costs of different financing alternatives. Notably, the reciprocal feature of interest-free loans from friends imposes a future obligation on the borrower and generates implicit financing costs. The final financing outcome hinges on the agent's complete evaluation and comparison of the aggregated financing costs from all available financing alternatives.

The innovation of this short article lies in its clarification of implicit costs in the seemingly zero cost of reciprocal loans. We argue that the future reciprocal obligation involved in the informal reciprocal loans generates nonpecuniary costs as the formal interest payment for cash-strapped borrowers. If agents ${ }^{2}$ When $\left[V\left(B_{S}^{I}, O ; \theta, Z\right)+\frac{R P_{2}^{I}}{1-\delta^{I}}+(1-\pi) B_{S}^{*}\right]-\left[r^{F} B_{S}^{F}+\frac{R P_{2}^{F}+C_{f}^{F}}{1-\delta^{F}}+(1-\pi) A^{F}\right]>0$, the agent will choose the formal loan. 
evaluate the reciprocal obligation with higher costs, they may forgo the seemingly cheaper informal loans and undertake the formal loans with interest charges. One limitation of our paper is that current data do not allow us to empirically compare financing costs from each financing source, which certainly deserves a further study when more detailed data are available.

\section{Acknowledgements}

We would like to thank the anonymous referees for their valuable comments that substantially improved the paper. Ruihan Liu (the corresponding author) gratefully acknowledges financial support from the Beijing Municipal Bureau of Finance and Beijing Municipal Bureau of Agriculture for their generous grants: Beijing Agriculture Innovation Consortium of Grain Industry (BAIC09-2017).

\section{References}

[1] Guirkinger, C. (2008) Understanding the Coexistence of Formal and Informal Credit Markets in Piura, Peru. World Development, 36, 1436-1452. http://www.sciencedirect.com/science/article/pii/S0305750X08000715 https://doi.org/10.1016/j.worlddev.2007.07.002

[2] Hoff, K. and Stiglitz, J.E. (1997) Moneylenders and Bankers: Price-Increasing Subsidies in a Monopolistically Competitive Market. Journal of Development Economics, 55, 485-518.

http://www.sciencedirect.com/science/article/pii/S0304387896004439 https://doi.org/10.1016/S0304-3878(98)00062-5

[3] Mansuri, G. (2007) Credit Layering in Informal Financial Markets. Journal of Development Economics, 84, 715-730.

http://www.sciencedirect.com/science/article/pii/S0304387806002021 https://doi.org/10.1016/j.jdeveco.2006.12.001

[4] Conning, J., and Udry, C. (2007). Rural Financial Markets in Developing Countries. Handbook of Agricultural Economics, 3, 2857-2908. http://ageconsearch.umn.edu/bitstream/28458/1/dp050914.pdf https://doi.org/10.1016/S1574-0072(06)03056-8

[5] Jain, S. (1999) Symbiosis vs. Crowding-Out: The Interaction of Formal and Informal Credit Markets in Developing Countries. Journal of Development Economics, 59, 419-444. http://www.sciencedirect.com/science/article/pii/S030438789900019X https://doi.org/10.1016/S0304-3878(99)00019-X

[6] Kochar, A. (1997) An Empirical Investigation of Rationing Constraints in Rural Credit Markets in India. Journal of Development Economics, 53, 339-371. http://www.sciencedirect.com/science/article/pii/S0304387897000205 https://doi.org/10.1016/S0304-3878(97)00020-5

[7] Turvey, C.G., Kong, R. and Huo, X. (2010) Borrowing amongst Friends: The Economics of Informal Credit in Rural China. China Agricultural Economic Review, 2, 133-147. https://econpapers.repec.org/paper/agsiaae09/51658.htm https://doi.org/10.1108/17561371011044261 